\title{
Fios da razão: Tradição e pluralidade da Umbanda em Pontal
}

\author{
Juliana Barros Brant Carvalho \\ José Francisco Miguel Henriques Bairrão
}

\section{RESUMO}

Neste artigo busca-se compreender a pluralidade da umbanda, uma tradição afro-brasileira, através de um estudo sobre a biografia de uma dirigente e a transmissão de seus saberes. Para tanto, interagiu-se com a comunidade pesquisada em posição de consulente nas cerimônias religiosas de um terreiro na cidade de Pontal, interior de São Paulo. Além disso, foram feitas entrevistas, registros em caderno de campo, fotográficos, de vídeos e de áudio. Encontrou-se que a heterogeneidade e o pluralismo da umbanda, quando examinados numa perspectiva etnopsicológica, evidenciam a insuficiência de algumas categorias acadêmicas que têm sido utilizadas para os compreender: nomeadamente o sincretismo, hibridismo, convergência, conversão e trânsito religioso. A múltipla pertença religiosa, vista como traço da modernidade em oposição ao tradicional, na umbanda parece ser uma condição da sua tradicionalidade, uma vez que a vida social e comunitária é mais determinante que princípios doutrinários em si mesmos.

Palavras-chave: umbanda, etnopsicologia; cultos afro-brasileiros; transmissão cultural.

\section{ABSTRACT}

\section{Lines of reason: Tradition and plurality of the Umbanda in Pontal}

This paper aims to comprehend the plurality of Umbanda, an Afro-Brazilian tradition, through a study about one leader's biography and the transmission of knowledge. For this purpose, the researcher interacted with the community as a participant in the religious ceremonies in a terreiro in Pontal, in the countryside of São Paulo. The leadership was interviewed, field notes were registered and photos, videos and audio were collected. It was found that the heterogeneity and the plurality of Umbanda, when analyzed from an ethnopsychological perspective, highlights that some academic categories used are not enough to understand those attributes, such as: syncretism, hybridism, religious transit, convergence and conversion. In this case, the multiple religious belonging, seen as a trace of modernity in opposition to tradition, seems to be in Umbanda the requirement to its traditionalism. Social and communitarian life are more decisive than the doctrine itself.

A umbanda é uma religião afro-brasileira, em que se nota no panteão espiritual a não separação bem definida entre sagrado e cotidiano, entre espíritos e pessoas. Não se estabelecem categorias rígidas nessa tradição composta pela combinatória entre orixás, guias (entidades espirituais) e santos, investigados em recentes trabalhos acadêmicos que discutem amplamente suas características (Bairrão, 2004, 2005; Barros \& Bairrão, 2015; Dias \& Bairrão, 2011; Macedo \& Bairrão, 2011; Martinez \& Bairrão, 2009; Rotta \& Bairrão, 2012). E também têm sido feitos estudos sobre o corpo (Jorge, 2013) e sobre o cuidado numa interface multicultural (Scorsolini-Comin, 2014a, 2014b) em consonância com essa espiritualidade.

As combinações, nomeadas por Birman (1983) de bricolagem entre elementos brancos, negros e indígenas da sociedade, são vistas principalmente como sendo o efeito da influência de religiões europeias, socialmente mais valorizadas, como o catolicismo e o kardecismo (Camargo, 1961), apesar de manter laços fortes e explícitos com as heranças indígenas e africanas (Silva, 2012), historicamente perseguidas e demonizadas, consideradas supersticiosas,

\section{Informações Autores}

J.B.B.C

http://orcid.org/0000-00034889-515X

Universidade de São Paulo Campus Ribeirão Preto Ribeirão Preto, SP

jubrantcarvalho@yahoo.com.br

J.F.M.H.B

http://orcid.org/0000-00016372-8873

Universidade de São Paulo Campus Ribeirão Preto -

Ribeirão Preto, SP

jbairrao@yahoo.com.br

\section{Direitos Autorais}

Este é um artigo de acesso aberto e pode ser reproduzido livremente, distribuído, transmitido ou modificado, por qualquer pessoa desde que usado sem fins comerciais. 0 trabalho é disponibilizado sob a dedicação Creative Commons CC-BY-NC.

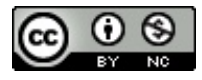




\section{H. INTERACÃO EM LF PSICOLOGIA}

Juliana Barros Brant Carvalho e José Francisco Miguel Henriques Bairrão mágicas e perigosas (Negrão, 1996, 2008). E teriam sido anexadas às práticas umbandistas religiões orientais e da Nova Era (Sanchis, 1997).

Contribui para esse sistema plural um sagrado vivido no dia a dia da comunidade (Brumana \& Martinez, 1991), cuja apreensão é estética e não metafísica, enunciada a múltiplas vozes que ressignificam dignificadamente experiências e memórias coletivas relacionadas ao abandono e à exclusão social (Bairrão, 2004). Os pretos-velhos, por exemplo, são espíritos reportados como ex-escravos, representativos de uma reversão daquele que viveu o desamparo e o desespero de ser despossuído de si mesmo na própria pele, e depois de morto cuida dos que o procuram, quiçá com problemas infinitamente menores dos que os sublimaram em elevados espíritos da umbanda (Dias \& Bairrão, 2011).

Outras inúmeras entidades espirituais, como caboclos, crianças, marinheiros, baianos e boiadeiros personificam-se em narrativas históricas e cenários geográficos (Macedo \& Bairrão, 2011), configurando-se numa interlocução entre o sagrado o social. Desse modo, significados religiosos permutam-se às vivências sociais, visto que essa espiritualidade em si torna-se ininteligível se não for interpretada mediante o crivo da experiência vivida.

Além disso, a relação entre doença e cura teria um papel fundamental na umbanda, exercendo uma importante função psicossocial no diagnóstico de enfermidades em grande parte da população brasileira (Negrão, 2009). E etimologicamente umbanda significa de fato uma medicina, uma prática de cura (Ribas, 1989).

Em tempos recentes, a umbanda vem sofrendo censuras e pressões de cunho intelectualista, marcadas pelo racismo, que visariam uma espécie de depuração étnica. Por um viés da superioridade branca, tentar-se-ia aproximá-la a um polo mais kardecista e apagar suas raízes africanas. Por um viés da re-africanização, tentar-se-ia um retorno à sua suposta origem mais pura, de limpar o que teria incorporado ao longo do tempo de outras tradições, nomeadamente do catolicismo popular ibérico ou mais precisamente da religião popular portuguesa (Espírito Santo, 1990). E na tentativa de resgatar uma identidade africana, descreveu-se a macumba paulista como uma forma deturpada de religião negra (Bastide, 1973), considerando-se a umbanda como a morte branca da feitiçaria negra (Ortiz, 1991). A partir de argumentos como esses, é compreensível que praticantes letrados tenham feito um esforço de restauração de uma africanidade apontada como luta por reconhecimento e visibilidade, defendida de forma ainda mais proeminente no candomblé (Hofbauer, 2012). Apesar disso, de acordo com Lepine (2009) essa tendência teria repercutido sem muito sucesso entre mães-de-santo antigas. Algumas delas ofereceriam resistência ao abandono ou substituição de referências cristãs aprendidas com antepassados, em prol de uma pretensa tradição mais africana inventada para propósitos contemporâneos (Capone, 2009).

Não obstante essa problemática, que leva a crer na umbanda a aceitação de outras religiões como desarticulação de suas raízes, Ferreti (2007) destaca que todas são oriundas de sínteses. Aponta-se no gradual desinteresse aos seus arranjos harmônicos uma questão mais endereçada à disputa cultural e acadêmica do que efetivamente seriam ponderadas suas sutilezas. Através de modelos hipoteticamente puros derivam-se conceitos que recriminariam as misturas, ambivalências e reformulações, entendidas como religiosidades simplificadas, confusas, e privilegiar-se-iam os contextos percebidos como originais.

Corbin (2008) nos adverte desse equívoco quanto ao uso do polêmico termo sincretismo. Segundo o autor, escolas de pensamento hegemônicas desqualificam outras tradições por uma ilusão de ótica inclinada a aprisioná-las em categorias superficiais e dogmáticas, alheias à sua lógica interna. $\mathrm{Na}$ realidade, tal olhar diacrônico motivar-se-ia por uma tendência histórica de pensar e distorcer o outro mediante conceitos que lhe são extemporâneos, como se a compreensão das suas razões e modos de ser tivesse de se procurar noutros lugares ou noutros tempos.

$\mathrm{Na}$ contramão de abordagens que induziriam a corrigir o que se encontra como dado, é defensável assumir a não-pureza como virtude. Para Sanchis (1997), a pluralidade de matrizes simbólicas afirma-se como a sociogênese religiosa do brasileiro. O heterogêneo seria a regra, apontando-se um resgate criativo de elementos do passado reorganizados em narrativas transformadas, que escapam às da elite intelectual e dominante. A ideia de pureza religiosa, anterior a uma suposta degradação contemporânea, seria um engano projetado retrospectivamente quer por um descompasso temporal, em uma análise que privilegiaria outra época e feita a partir das suas supostas fontes culturais, quer por se negar a originalidade da lógica de sínteses, perdendo-se o que se afirma de inédito e atual.

Com a retomada desse tópico, juntamente ao do uso dos conceitos, coloca-se uma interrogação sobre o retrato mencionado anteriormente a respeito da umbanda. Valendo-se de informações relevantes quanto às suas formas particulares de expressão, faz-se necessário saber em que medida, no plano das vivências brasileiras, estaria ainda em consonância com suas matrizes africanas. Quando vista por dentro, parece ser menos atida a explicações racionalizantes sobre si, especialmente nas manifestações que comportam o sensível, pela via dos sentidos do corpo, arquitetados a enunciados em narrativas sem palavras, as quais findariam-se reduzidas à desorientação por um pensamento intelectualizado. 


\section{INTERACÃO EM LF PSICOLOGIA}

É sabido que objetos, plantas e elementos da natureza atuam como metáforas e metonímias do sagrado umbandista, inscrito também no corpo dos médiuns, nas cores, aromas, gestos, no som, nas músicas e na dança (Bairrão, 2005). Porém ainda não foi suficientemente estudado como esses repertórios espirituais aparecem nas histórias de vida dos dirigentes, uma vez que seu papel é manter e transmitir fundamentos da religião. Neste artigo visa-se responder à questão deixada em aberto e saber se essas vivências respaldam-se nas mesmas raízes africanas identificadas por Bairrão e Leme (2003) em outra comunidade umbandista no interior de São Paulo.

Visto que populações africanas compuseram parte substancial do sudeste brasileiro e mantiveram memórias, sendo agentes da sua própria história, em uma espiritualidade feita em casa dentro das senzalas, nas famílias extensas (Slenes, 2011), essa cultura, transmitida na linguagem e no cotidiano, estaria em sintonia com um devir afinado com a contemporaneidade, com a nova terra, a brasileira. E permitiria composições flexíveis, sobreposições e fusões (Leite, 1992, 1996), mostradas em narrativas sobretudo estéticas. Kramer (1993) explicitou como saberes africanos se trasmitem esteticamente no cotidiano e nos objetos rituais. Um equivalente africano da nossa ciência teria sido na perspectiva do europeu interpretado como arte primitiva. Notou-se nos objetos artísticos ou sagrados, assim como nos cultos de máscaras e de possessão, uma apresentação de detalhes do estrangeiro, o qual no imaginário dessa população "pode ser um deus vestido de homem" (Kramer, 1993, p. 11), como produção de um saber e de um poder a seu respeito.

Essa prática, entendida aos olhos ocidentais como religiosa ou artística, seria um esforço coletivo de conhecer e incluir o outro, o desconhecido, de forma não redutora ao si mesmo. Para Kramer, as máscaras e os objetos rituais no sistema simbólico africano correspondem a um modo de pensar permanentemente aberto, regulado por alianças e trocas. Politicamente, as semelhanças entre eu e outro são baseadas em critérios heterogêneos que, em última instância, afirmariam a autonomia e o fortalecimento do coletivo. Enquanto que os sistemas simbólicos do europeu seriam derivados de modelos homogêneos, como as políticas centralizadoras e escravistas, impondo-se uma barreira entre o fora e o dentro numa lógica de dominação e poder, de manutenção das diferenças. E como sublinhou Bairrão (2011), este pensamento encontrado em culturas africanas parece atuar tal como a psicanálise supõe o sujeito, segundo a qual parte do ser é estrangeira do eu.

0 pensamento igualmente heterogêneo pode ser percebido na não separação radical do mundo dos vivos e dos mortos. Para Kopytoff (2012) concepções de família na África abrangem o ente morto nas relações comunitárias, entendido como um avô. Dessa forma, uma barreira que caracterizaríamos com religiosa entre os vivos e os mortos não chega necessariamente a ser vista em contextos africanos como uma cisão no social. Os nossos mortos não se exilam no Além, participam da família do aquém.

Esse panorama ilumina elementos para o estudo feito em uma comunidade antiga na região de Ribeirão Preto, com o objetivo de compreender na vida de seus principais protagonistas como as narrativas umbandistas se configuram e se renovam. À luz de suas concepções próprias, discute-se a composição de um panteão naturalmente diverso, podendose contribuir para a reflexão sobre os descompassos identificados entre algumas vertentes teóricas e a prática no campo afro-brasileiro.

\section{MÉTODO}

Com esse propósito, foram coletados dados etnográficos ao longo de cinco anos no terreiro "Pai Candinho pela razão Pai Sebastião pela razão Ogum Rompe Mato". Interagiu-se com a comunidade pesquisada em posição de consulente, participando-se dos rituais e do cotidiano a fim de conhecêlos, de conversar com os participantes e de fazer registros em caderno de campo, fotográficos e de vídeo. Visitou-se a comunidade semanalmente e foram feitas entrevistas abertas com a dirigente, gravadas e transcritas, que compõem parte dos resultados reportados principalmente à sua história de vida, remontando ao surgimento do terreiro.

Para efeito de análise, foram consideradas não apenas as informações oferecidas pelos participantes humanos, que compartilharam saberes a respeito das suas vivências religiosas, mas também os dizeres dos espíritos, dos rituais, dos objetos, dos modos de vida, das conversas informais e dos acontecimentos, prestando-se atenção em tudo o que sucede e circula socialmente produzindo sentidos reconhecidos pela comunidade, um tipo de procedimento que tem sido denominado de escuta participante (Bairrão, 2005). 0 que se ressaltou foram repetições que apareceam na comunidade como um todo, sendo o sujeito da pesquisa a memória coletiva, expressa não necessariamente por meio de palavras, de modo que a pessoa do pesquisador, incluindo as suas sensações, sentimentos e percepções, foram instrumento para esta interação (Bairrão, 2015).

\section{RESULTADOS E DISCUSSÃO}

A comunidade pesquisada situa-se na cidade de Pontal, região de Ribeirão Preto, interior de São Paulo. Foi fundada por Dona Joana, uma importante médium umbandista que 


\section{MI* INTERACÃO EM LF PSICOLOGIA}

nasceu no Rio de Janeiro e posteriormente morou em São Paulo. Um dos seus filhos foi curado de uma doença grave no terreiro onde frequentava. Nesse lugar, muito tempo depois, um caboclo deu-lhe a missão de abrir um terreiro em Pontal. Era viúva e já com os filhos adultos quando se mudou sozinha para o pequeno município que fica contíguo à zona rural. Feito isso, arrumou um pequeno salão emprestado de uma comunidade evangélica e ali passou a oferecer atendimentos espirituais para as pessoas da cidade e das fazendas da região.

Logo após sua chegada, foi procurada para ajudar uma mulher considerada louca, que tinha atitudes como correr para o meio do mato, sentar-se debaixo de uma árvore e ficar com um graveto riscando o chão. Era descendente de indígenas, moradora na colônia da fazenda onde trabalhava. $\mathrm{Na}$ mesma propriedade trabalhava seu marido, descendente de africanos, que era chamado pela filha do casal quando esses episódios aconteciam. Atento à espiritualidade, recorreu à Dona Joana. Conta-se que depois de ser atendida, essa consulente passou a incorporar um caboclo e deixou de apresentar os sintomas de loucura. Esse contexto compôs o princípio dessa comunidade umbandista.

Na mesma colônia onde essa família residia, outras pessoas solicitaram e tiveram melhora com o auxílio de Dona Joana, tal como uma mulher negra que tinha doenças na pele e com muita frequência ficava deitada na cama por dias seguidos, com uma espécie de depressão, conforme relatam. Curou-se depois de ser atendida e dedicou-se à sua profissão de costureira, confeccionando por muitos anos as saias e calças brancas usadas pelos médiuns no terreiro, como agradecimento à comunidade religiosa. Nessa fazenda havia uma escola para os trabalhadores e seus filhos que fossem brancos, como os familiares de imigrantes europeus e, portanto, quem era negro não podia frequentá-la. Esta imposição destinava a essa família afrodescendente o trabalho em funções domésticas e braçais. Por esse motivo, o casal mudou-se da zona rural para a cidade com os filhos, decididos de que eles deveriam estudar.

Um deles é Dona Helena, que nessa época tinha 14 anos. Uma das características marcantes da comunidade é o cuidado com as crianças. Tendo sido uma criança cuja mãe apresentava problemas, foi acolhida e passou a acompanhar Dona Joana como sua ajudante nas práticas espirituais. As crianças são também uma categoria da espiritualidade, e essa mãe-de-santo fazia anualmente uma grande procissão em sua homenagem, com faixas em que estava escrito "Saravá Cosme e Damião e Daum" e "Salve a umbanda salve o povo de Pontal" (ver figura 1), como manifestação do orgulho da comunidade pela religião.

No culto africano, os Ibeji são entidades gêmeas, repre- sentantes de duas crianças, o que no contexto da umbanda corresponderia a "Cosme e Damião". E muitas vezes são representados junto a uma entidade menor no meio, Idowu, sonoramente parecido com o que na umbanda nomeia-se Doum, correspondente à unidade dos dois. Nesse caso, com uma pequena mudança lê-se "Daum", uma forma sutil de dizer "dão um".

Na foto abaixo (Figura 1), tirada em meados de 1950, essa importante mãe-de-santo usa uma coroa, concedida à Madrinha da comunidade. Quando era viva realizava atendimentos na sua casa, no terreiro e na casa das pessoas. O cuidado aparece dentro e fora do terreiro, endereçado a todos os tipos de necessidades. Além dos rituais tipicamente umbandistas, a Madrinha liderava sessões espíritas de mesa branca, onde praticava as operações espirituais, rituais voltados para a cura, tais como se encontram em algumas vertentes associadas ao espiritismo kardecista. Utilizava elementos como flores, copo de água, fitas e velas coloridas, algodão, tesoura e mercúrio, auxiliada por espíritos da linha de cura, como os ciganos, característicos da umbanda, também conhecidos como a linha do oriente. O espiritismo kardecista e os ciganos, aparentemente exteriores ao universo umbandista, são entendidos como uma especialidade dedicada à cura, e, portanto, fazem parte das práticas religiosas dessa comunidade.

Procurou ajuda de Dona Joana um dos fazendeiros da região que tinha uma filha acometida por uma doença grave e não respondia a nenhum tratamento médico. Como agradecimento pela cura da filha doou-lhe um terreno na cidade de Pontal. Nesse terreno foi construído um novo terreiro, o qual funciona atualmente e acomoda uma comunidade maior. Durante grande parte de sua vida esta Madrinha atendeu e desenvolveu espiritualmente muitas pessoas.

Dona Helena é uma delas, que passou durante sua vida adulta por uma série de abortos, sendo alertada por médicos do perigo de engravidar e, caso isso acontecesse corria risco de vida. Dona Joana recomendou-lhe uma iniciação no candomblé, pedindo ajuda a outros pais-de-santo. Com isso, novamente os saberes de religiões diferentes parecem somar esforços na solução de um problema. Após passar pelo longo processo que é a iniciação no candomblé, a cabeça raspada e recolhida na camarinha até o dia da saída do santo, Dona Helena conseguiu com sucesso engravidar e teve cinco filhas. A cura da mãe com o desenvolvimento mediúnico na umbanda, e a sua própria no candomblé são assumidos como um compromisso para a vida toda.

Dona Helena aprendeu os ofícios da religião com Dona Joana, chamada atualmente de Madrinha Velha, e herdou o cargo de Madrinha quando aquela faleceu, tornando-se zeladora-de-santo, como costuma dizer, responsável pela conti- 


\section{INTERACÃO EM STSICOLOGIA}

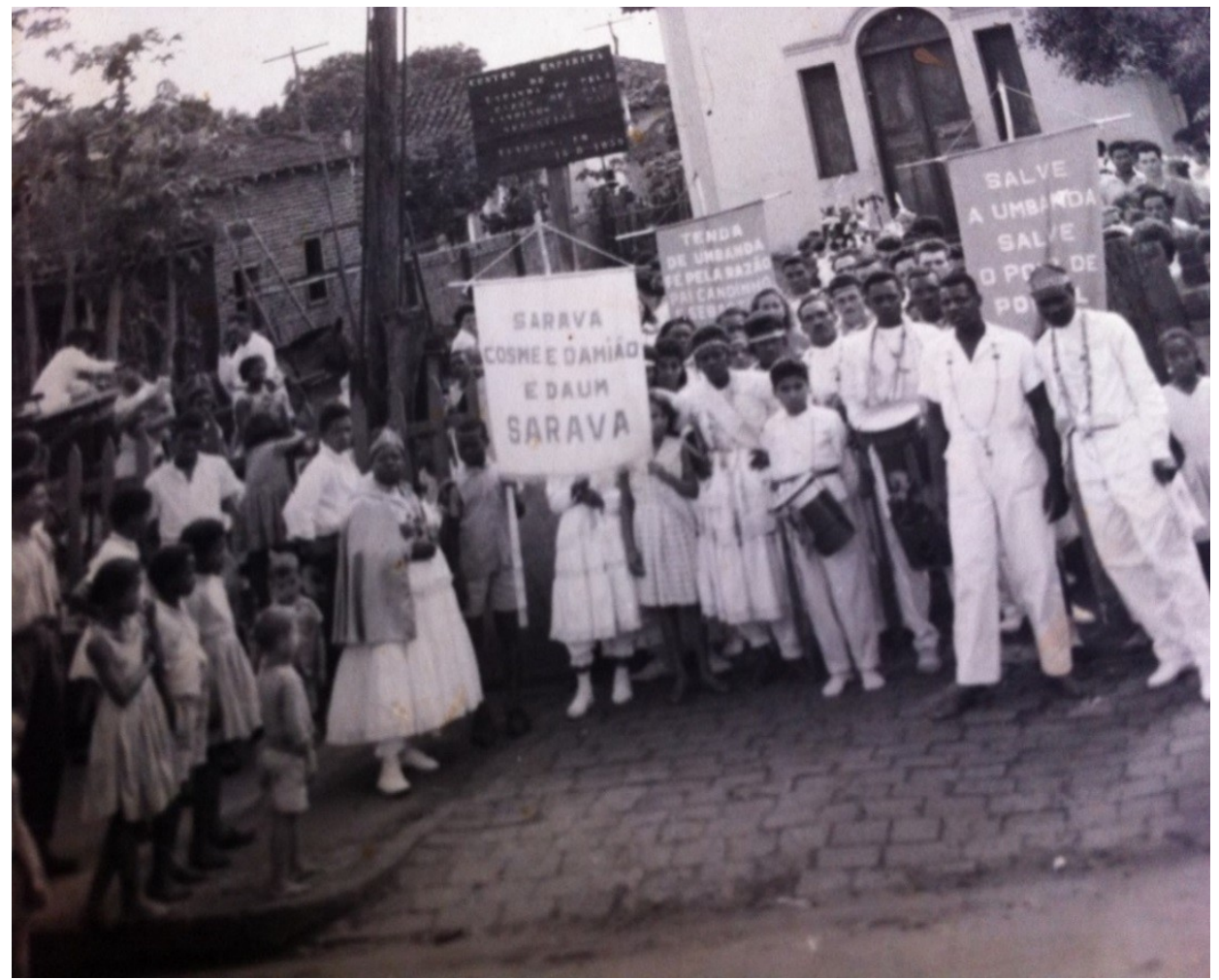

Figura 1: Cortejo durante a festa de Cosme e Damião. Fotografia tirada da foto original que pertence à máe-de-santo do terreiro.

nuidade do terreiro. Embora tenha continuado com as obrigações no candomblé, não deixou de tocar a tradição umbandista. As duas religiões hoje convivem sem que uma apague a outra. Dedica-se diariamente aos seus filhos-de-santo, dá continuidade ao ritual da mesa branca, joga búzios e faz iniciações no candomblé quando necessárias, de modo que a comunidade se fortalece enriquecida pela diversidade de procedimentos compartilhados no mesmo espaço, na medida em que os adeptos podem precisar (ou gostar) mais de um ou do outro. Afeita ao gosto do cliente, a comunidade parece lidar com uma efetiva autonomia dos seus membros e da dirigente. A necessidade aplica-se à dimensão não apenas de escolha, mas de situações particulares que demandam diferentes providências. Tal como nas sessões da mesa branca, onde se lê o livro $O$ evangelho segundo o espiritismo, de Alan Kardec, em torno de uma mesa coberta com um pano branco, e depois se recebem as entidades espirituais. As entidades incorporadas são as mesmas da umbanda, como caboclos, crianças e pretos-velhos. Muda-se apenas a sua apresentação visual, sentados em cadeiras, e sem o uso dos seus objetos rituais como charuto para caboclos, cachimbo para pretos-velhos, brinquedos para crianças.

Os rituais do espiritismo, da umbanda e do candomblé são feitos separadamente. Segundo Dona Helena, "é só saber separar, tudo certinho, (...) tem que dar oportunidade pra tudo, se dá oportunidade não acaba", deixando claro que há conhecimentos distintos, mas funcionam de maneira porosa, flexível e tolerante. Privilegia-se através do cuidado o caso a caso, e os próprios espíritos em circulação não excluem os diferentes meios com que se abrange a comunidade como um todo.

Observou-se numa festa em homenagem a Omulu (Obaluaiê), divindade ligada à cura, o preparo de comidas para todos os orixás, colocadas em cima de esteiras de palha no meio do salão onde acontecem as giras (os ritos) da umbanda. Ali foram também colocadas imagens do congá (altar) umbandista, dos santos católicos associados às divindades afros: Santa Bárbara/ lansã, São Gerônimo/Xangô, São Sebastião/Oxóssi, São Jorge/Ogum, Nossa Senhora Aparecida/Oxum, Nossa Senhora/Yemanjá. À frente deles foram colocados seus pratos característicos enfeitados com flores, incluindo-se os pretos-velhos e suas comidas preferidas, bolo de fubá e vinho tinto, um tipo de disposição que não se veria nos moldes tradicionais de um Olubajé, festa em geral celebrada no candomblé.

Dentro da própria residência de Dona Helena são feitas as sessões de 'mesa branca' e as iniciações de candomblé. Ou 


\section{W'INTERACÃO EM ET. PSICOLOGIA}

seja, a sala da sua casa, a cozinha e o terreiro estão no plano do sagrado e ao mesmo tempo parte do cotidiano. Verifica-se um espaço de pluralidade na convivência entre pessoas e espíritos. E um consórcio entre candomblé, kardecismo e umbanda, permitindo-se deslocamentos e equivalências, como mostra a fala de Dona Helena, que consegue "dar oportunidade pra tudo", ser acessível a todos.

Os caminhos trilhados pela Madrinha anterior e pela atual mostram a continuidade de uma espiritualidade compreendida de maneira muito particular. Mostra-se na foto a seguir ( $\mathrm{Fi}$ gura 2) a importância dos detalhes, das cores, dos objetos e imagens reunidas em um terreiro de umbanda.

Mediante um ethos que inclui a todos, a umbanda enfileira os mitos e saberes correspondentes à intensa mestiçagem de povos, típica da sociedade brasileira. Pode-se variar o lugar ritual sem perderem-se as propriedades inerentes à comunidade religiosa, cuidando-se de diferentes ancestralidades.

Evidencia-se nesse estudo uma umbanda acolhedora, uma casa com as portas abertas para as pessoas e para a sua diversidade religiosa. Aspectos depreciados na sociedade brasileira, como marcas indígenas e africanas, estão articulados à origem rural dos integrantes que contribuíram para a formação e o nascimento do terreiro, da comunidade religiosa. Ao mesmo tempo em que são representados no panteão em um lugar de destaque, como provedores de cura.

As biografias dos praticantes tecem uma experência histórica como fios condutores do religioso. Vivências espirituais se expressam no âmbito do familiar, como se destaca na festa do velho Obaluaiê, quando todas as divindades comem juntas na mesma mesa. Nessa elaboração, a mãe-de-santo compreende a razão de ser das divindades do candomblé, os orixás, trazendo uma festa importante dessa tradição para a sua umbanda, preservando a presença de pretos-velhos (os avôs) no banquete sagrado. As razões diversas aparecem concretamente no nome do terreiro, Pai Candinho pela razão Pai Sebastião pela razão Ogum Rompe Mato. Esses fios alinham as entidades chefes do terreiro, como Oxóssi, o rei das matas (representado por São Sebastião), e Ogum Rompe-mato àquelas vivências indígenas e afrodescendentes situadas na zona rural do interior paulista.

É notável a profunda afinidade entre as caracterísiticas africanas e aspectos do ethos umbandista. A cura reforça o compromisso com a espiritualidade e com as pessoas nas vivências de Dona Joana, o que aparece de maneira semelhante nas vivências de Dona Helena, ao assumir a umbanda como anfitriã do espiritismo kardecista e do candomblé, co-

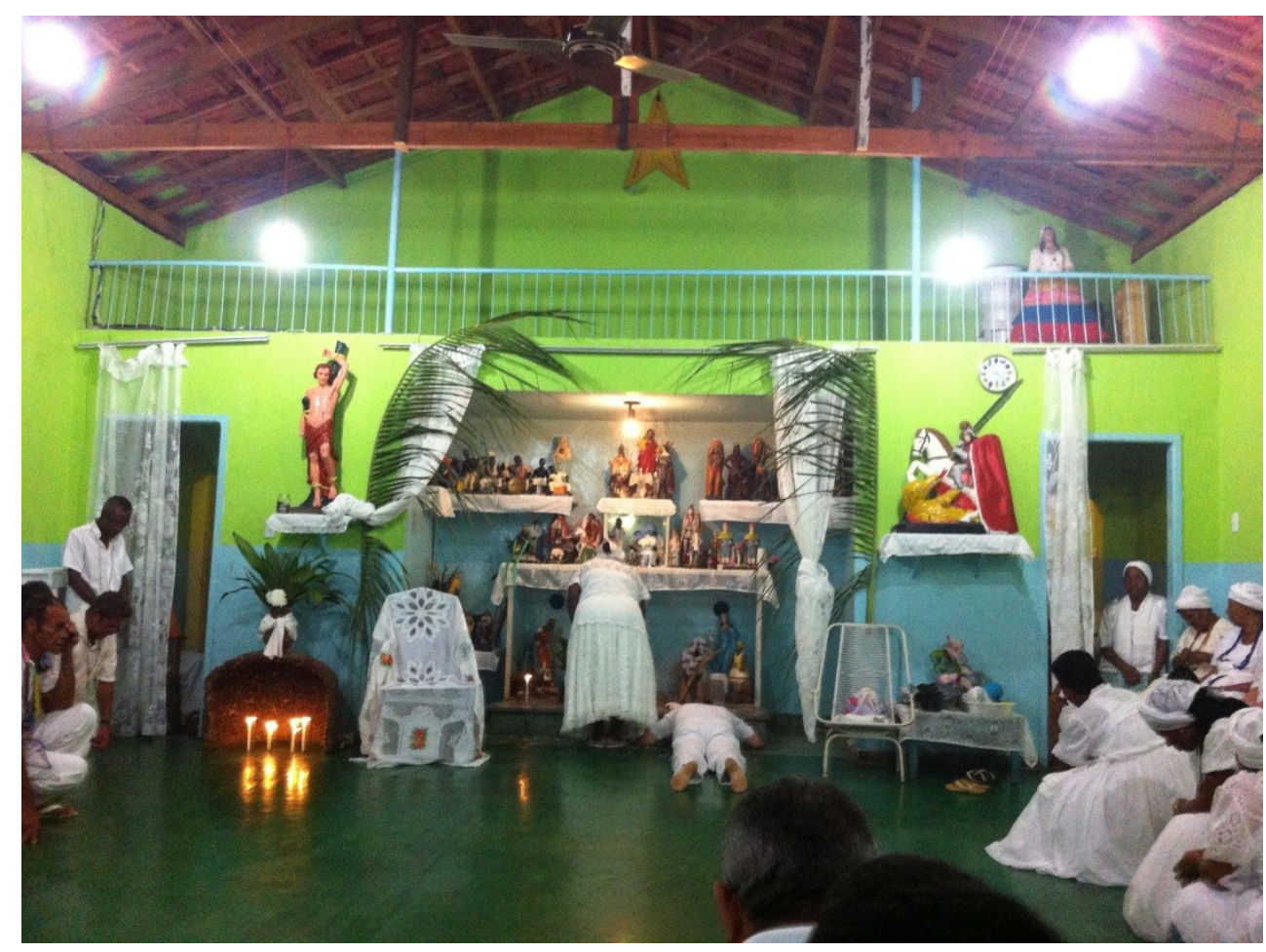

Figura 2: Senhora Maria Helena no centro do terreiro em Pontal, em 2014. Fotografia tirada por um dos autores. 


\section{- H. INTERACÃO EM LF PSICOLOGIA}

mo partes de um mesmo percurso religioso. Os rituais são entendidos como o cuidar e ser cuidado pelos ancestrais. A raiz cultural aparece sem exclusividade, não dogmática, entretanto, profundamente implicada em valores transmitidos na prática, num fazer estético, mas principalmente ético. Enlaces entre o mundo vivido e o sagrado podem transformar a prática ritual, mas não significam a perda ou degradação da tradição.

Isso problematizaria a depreciação crítica do que malfadadamente possa ter sido considerado sincretismo em detrimento de uma suposta pureza cultural, uma vez que o que transparece na realidade é o seu contrário: um olhar que apaga um modo próprio de ser includente da alteridade e preservador de uma convivência pacífica com o heterogêneo, que boa parte da África e a umbanda preservam em comum.

A união harmônica com o Outro se vê na figura de Jesus geralmente encontrada nos altares da umbanda com os braços abertos, como afirmação de valores africanos, como acolhimento e alegria e não de sofrimento (Bairrão \& Leme, 2003). A assimilação do sagrado cristão entre populações escravizadas, na incorporação dos modos de vida e símbolos do colonizador, faria referência a um modelo cultural próprio, não deixando de se comunicar com suas heranças (Souza, 2002).

Salienta-se a insuficiência de análises que apontam na pluralidade da umbanda um desgaste do tradicional. Diante disso, quais conceitos tal como a ideia do sincretismo, tantas vezes aplicada a situações análogas àquelas com que nos deparamos neste estudo, disporíamos na literatura a esse respeito? Seriam pertinentes ao que pôde ser observado?

Sanchis (1997) descreve o sincretismo como uma disposição cultural dos brasileiros em transpor o singular a religião para um crescente plural as religiões, o que sem dúvida constitui no campo religioso do Brasil a sua transformação mais significativa (p. 28). Devido a um esgotamento desse conceito, Engler (2009) sugere a ideia de hibridação para descrever a pluralidade umbandista apontada como um processo social e histórico complexo, associado à intensa mestiçagem de povos. No entanto, essa reciclagem conceitual ainda permaneceria limitada por categorizar o fenômeno visto na umbanda, sem contudo elucidar como a tradição desvincula-se ou neutraliza os modelos excludentes com os quais se hibridiza.

Outro conceito próximo desse modo de ser é o trânsito religioso, utilizado para se pensar a pertença concomitante de espiritualidades diversas. Apontam-se nas denominações religiosas aparentemente díspares elementos comuns (Almeida \& Montero, 2001), frisando-se um sagrado mais abrangente do que o demarcado pela instituição religiosa (Rabelo, 2015). A mesma compreensão aplicável ao tema é o múltiplo pertencimento religioso, salientado por Roberts
(2010) como resultado de reformulações e descontinuidades presentes no mundo contemporâneo. A liberdade de grupos religiosos e adeptos contrapor-se-ia à rigidez de discursos ortodoxos que podem oprimir ou apagar as diferenças. Categorias populares cada vez mais frequentes esquivar-se-iam de modelos padronizados. Porém, encontramos na comunidade pesquisada diferentes matrizes integradas à mesma instituição religiosa; no mesmo local o consulente encontra uma variedade de denominações. 0 dentro e o fora da tradição são fluidos, assim como casa e terreiro, como partes da mesma espiritualidade.

Dois contrapontos interessantes, a convergência religiosa e a conversão, são indicados por Paiva (1999) ao ressaltar o encontro entre religiões diversas, a alteridade, como uma condição transformadora na forma como os adeptos se colocam em relação a si mesmos e à sua comunidade religiosa, de mais tolerância. Do ponto de vista psicológico, haveria na conversão uma mudança imaginária, superficial; e na convergência uma mudança simbólica, reconfigurando uma nova subjetividade do sujeito em relação à sua experiência religiosa.

Ora, na umbanda observa-se um tipo de mudança bastante específico, uma adesão do eu ao outro sem que isso se caracterize como imaginária ou simbólica, pois se mantém uma vivência religiosa prévia aliada a uma recombinação profunda das regras do jogo religioso, as separações, o que autorizaria e legitimaria a concomitância de diversas religiões, mesmo que ordenadas em ritos distintos.

Vale ressalar sobre as diferenças que a alteridade, o outro, aparece historicamente hierarquizado na perspectiva do colonizador com a ideia de conversão, no apagamento de crenças supostamente primitivas' de determinado grupo entendido como um sagrado imperfeito. Já em uma cosmovisão que desejaria ser o outro, esta incorporação seria senão uma afirmação de si (Bennagia, 2009). Este horizonte põe em cheque narrativas etnocêntricas que tendem a excluir o lugar de fala própria do outro por meio de um modelo de pensamento que o vê como deficitário, e tentar-se-ia melhorá-lo, aperfeiçoá-lo colonizando-o. Ao mesmo tempo em que se denunciam mal-entendidos entre conversor e convertidos.

Nesse sentido, a substituição de uma visão de mundo por outra no passado brasileiro teria ocorrido desde as populações não-cristãs, que quando não exterminadas eram batizadas por imposição do Estado católico e dos proprietários de terra. Na prática, importava mais parecer do que ser católico. As religiosidades divergentes, vistas como distorções, heresias, seriam experiências subjetivas e filosofias de vida desconectadas do discurso dominante. Associadas ao curandeirismo do negro liberto e sem lugar na sociedade que o escravizou, considerado uma ameaça, os grupos afro-brasi- 


\section{H. INTERACÃO EM LF PSICOLOGIA}

Juliana Barros Brant Carvalho e José Francisco Miguel Henriques Bairrão leiros foram perseguidos com uma política branca. Desprotegidos pela lei, passariam a defender seus recursos culturais ocultando-os (Negrão, 1996, 2008), o que explicaria em parte a assimilação dos santos católicos e do kardecismo.

Mediante uma investigação etnopsicológica da forma como as pessoas compreendem por dentro da comunidade essa heterogeneidade e pluralismo, encontrou-se uma religião que dialoga com essa tendência de apagamento, oferecendoIhe um modelo alternativo. Convertidos às regras do colonizador e à visão de mundo moderna, a força de resistência cultural encontrada na umbanda seria a apropriação das normatizações das elites traduzidas para a linguagem popular. As tradições antigas no contexto afro-brasileiro, se vistas como sistemas ricos e sofisticados, aceitando-se o entendimento do ethos africano conforme Kramer (1993) e Kopytoff (2012), percebe-se no âmago da sua metamorfose o alicerce de algo talvez muito mais africano do que europeu.

Ainda que se assista razão a como teriam incorporado outras tradições fazendo jus a um histórico de violência e colonização, não seria menos verdade que as linhas de resistência a essa opressão possam ter-se guiado não apenas por concessões, mas também tomado partido favorável a formas de pensamento e visão de mundo propriamente africanas. Assim, na umbanda o ser umbandista não excluiria o ser católico, ser espírita ou ser de candomblé. Apenas os termos não a definiriam, e sim desdobrariam-se como um fazer inerentemente acolhedor do outro.

Indica-se no contexto afro-brasileiro a hipótese de coexistirem fronteiras menos rígidas do que os termos sincretismo, hibridismo, trânsito religioso, multiplo pertencimento religioso, ou mesmo conversão e convergência religiosa alcançam. 0 que se supõe é o plural como tradicionalidade. A síntese coletiva, identificável em alguma medida como o 'ser brasileiro', preserva sua própria diversidade em uma lógica a que se tenha chegado na umbanda não apenas como obra de reação ao mundo branco, mas de um protagonismo altivo de outros critérios e valores originários, que se enunciam como prática espiritual autônoma e insubordinada a coações externas.

\section{CONCLUSÃO}

A umbanda parece atuar como um radar social para um sagrado que reúne vivências singulares, muitas vezes destituídas de lugar na sociedade hegemônica. Essa espiritualidade, baseada em uma concepção de sagrado não apartada do cotidiano, e não representada por abstrações míticas e nem congelada num tempo outro, enuncia-se em narrativas sensíveis e vividas no presente.

Este estudo também deixa evidente um tipo de liderança que atua de forma peculiar e atenta à diversidade de pessoas e sua heterogeneidade religiosa, possivelmente presente em outros contextos umbandistas e afro-brasileiros. De acordo com as histórias de vida relatadas, a luz divina parece refletir as diferentes tonalidades do humano. Simplificar o protagonismo desses grupos significaria privilegiar determinadas formas de pensar sobre outras. Com isso, a pesquisa em religião não se finda em primeira mão, podendo estar implicada em outros setores da vida social e cultural que, justamente por obedecerem a regras ancestrais, mostram-se permeáveis ao que the rodeia.

Nesses saberes, a prática religiosa faz menos sentido na esfera do pertencimento individual do que como linhagens espirituais, que não são identidades atemporais, reconhecidas na rede simbólica e nos acontecimentos do coletivo, sem prender-se a um conjunto de regras fixas nem a um grupo de especialistas.

No lugar de uma única doutrina que determinaria a suas características prévias, nota-se uma filiação espiritual motivada pela prática do cuidado ligado às especificidades da população. A prática varia mais em função de um eixo conectado com as características e implicação do adepto, como percepção ética e estética do outro, do que apegada a crenças religiosas.

O que se observou no contexto pesquisado foi uma forma de elaboração da experiência religiosa que mantém as diferenças sem apagá-las. Mudanças na forma de praticar a umbanda não significam um rompimento com suas origens. Há a mutação no âmbito doutrinário, em roupagens que não correspondem à sua especificidade religiosa, e ao mesmo tempo a manutenção de um fazer espiritual, e de uma visão de mundo ligada a recursos culturais antigos que parecem indicar um empréstimo de um modo de ser afro-brasileiro a outros contextos e linguagens. 0 que se aponta na literatura sobre a umbanda como a soma de outras tradições pode ser visto no fundo como um tipo de espiritualidade em que não importa a forma, mas o fazer. 0 que lhe é mais tradicional seria a sua capacidade de sempre se refazer original.

Reforçam-se de maneira criativa laços e memórias em coletividade em sintonia com problemáticas sociais atuais. Transmite-se um legado ético e religioso que pode atuar disfarçadamente, em que a peça-chave de sua expressão é a experiência social, que reanima a sua transmissão. 0 que inova e se renova na comunidade é a forma particular como sociabilidade e espiritualidade se imbricam, e a percepção das necessidades humanas, por intermédio das lideranças umbandistas, com base em critérios rigorosamente afinados com valores em que o externo e o interno, assim como o morto e o vivo podem ser intercambiáveis.

0 que se deixa patente no presente estudo pode possivelmente ser transportado para investigações em outras comu- 


\section{Ha mereacio ET. PSICOLOGIA}

nidades, tendo como desafio entender suas denominações próprias, sem reduzi-las a uma análise exterior à sua dinâmica. Com isso, faz-se necessário repensar a aplicabilidade dos conceitos apresentados ao longo da discussão, para não aprisionar categorias do sagrado afro-brasileiro supondo-se um retorno a elementos isolados de trocas culturais, estáticos, não se reconhecendo a manutenção de um ethos africano e suas obrigatórias vinculações com o vivido e sua configuração no contexto social brasileiro.

\section{CONTRIBUIÇÃO DE CADA AUTOR}

J.B.B.C. e J.F.M.H.B. foram responsáveis pela obtenção de financiamento bem como contribuíram para a conceitualização, a investigação, a redação inicial do artigo (rascunho) e pela redação final (revisão e edição) do presente artigo.

\section{DECLARAÇÃO DE CONFLITOS DE INTERESSES}

Os autores declaram que não há conflitos de interesses no presente artigo.

\section{DECLARAÇÃO DE FINANCIAMENTO}

$\mathrm{O}$ trabalho de pesquisa foi financiado pela bolsa concedida pela agência CAPES.

\section{REFERÊNCIAS}

Almeida, R. de, \& Montero, P. (2001). Trânsitos religiosos no Brasil. São Paulo em Perspectiva, 15(3), 92-101.

Bairrão, J. F. M. H. (2004). Sublimidade do mal e sublimação da crueldade: Criança, sagrado e rua. Psicologia: Reflexão e Crítica, 17(1), 61-73.

Bairrão, J. F. M. H. (2005). A escuta participante como procedimento de pesquisa do sagrado enunciante. Estudos de Psicologia, 10(3), 441-446.

Bairrão, J. F. M. H. (2011). A propósito do Outro, etnográfico e em psicanálise. Filosofia Aurora, 23(33), 345-358.

Bairrão, J. F. M. H. (2015). Faire de l'ethnographie avec la psychanalyse; les Psychologies d'un point de vue empirique. Cultures-Kairós- Revue d'anthropologie des pratiques corporelles e des arts vivants, 5. Recuperado em 23/07/2017 de http://revues.mshparisnord.org/cultureskairos/index.php?id=1180

Bairrão, J. F. M. H. \& Leme, F. R.(2003). Mestres bantos da Alta-Mogiana: Tradição e memória da umbanda em Ribeirão Preto. Memorandum, 4, 05-32.
Barros, M. L. \& Bairrão, J. F. M. H. (2015). Performances de gênero na umbanda: A pombagira como interpretação afro-brasileira de "mulher". Instituto de Estudos Brasileiros, 62, 126-145. http://dx.doi.org/10.11606/issn.2316-901X.v0i62p126-145

Bastide, R. (1973). Estudos afro-brasileiros. São Paulo: Perspectiva.

Benaggia, G. (2009). Conversão, com versões: A respeito de modelos de conversão religiosa. Rio de Janeiro: Revista Religião e Sociedade, 29(1), 200-222. http://dx.doi.org/10.1590/S0100-85872009000100009

Birman, P. (1983). O que é Umbanda. São Paulo: Brasiliense.

Brumana, F. G. \& Martinez, E. G. (1991). Marginália sagrada. Campinas: Unicamp.

Camargo, C. P. F. de (1961). Kardecismo e umbanda. São Paulo: Pioneira.

Capone, S. (2009). A busca da África no candomblé: Tradição e poder no Brasil. Rio de Janeiro: Pallas.

Corbin, H. (1969). Creative imagination in the Sufism of Ibn'Arabi (R. Manhein,Trad.). Princeton: Princeton University.

Dias, R. N. \& Bairrão, J. F. M. H. (2011). Aquém e além do cativeiro dos conceitos: Perspectivas do preto-velho nos estudos afro-brasileiros. Memorandum, 20, 145-176.

Engler, S. (2009). Umbanda and hybridity. Numen, 56(5), 545755. http://dx.doi.org/10.1163/002959709X12469430260084

Espírito Santo, M. (1990). A religião popular portuguesa. Lisboa: Assírio \& Alvim.

Ferreti, S. F. (2007). Sincretismo e religião na festa do divino. Anthropológicas, 18 (2),105-122.

Hofbauer, A. (2012). Pureza nagô, (re)africanização, dessincretização. Vivência, 1(40), 103-119.

Jorge, E. F. C. (2013). É no corpo que o santo baixa! Considerações sobre o corpo nos transes religiosos afro-brasileiros. Identidade!, 18 (1), 122-132.

Kopytoff, I. (2012). Ancestrais enquanto pessoas mais velhas do grupo de parentesco na África. Cadernos de campo, 21(21), 233-250. http://dx.doi.org/10.11606/issn.23169133.v21i21p233-250

Kramer, F. (1993). The red fez: Art and spirit possession in Africa. (M. R. Green, Trad.) Londres: Verso.

Leite, F. (1992). A questão da palavra em sociedade negroafricanas. Em J. E. Santos (Org.), Democracia e Diversidade Humana, desafio contemporâneo (pp. 35-41). Salvador: SECNEB.

Leite, F. (1996). Valores civilizatórios em sociedades negroafricanas. Africa, 18-19(1), 103-118. http://dx.doi.org/10.11606/issn.2526-303X.v0i18-19p103118 


\section{- H* INTERACÃO EM LF PSICOLOGIA}

Leme, F. R. \& Bairrão, J. F. M. H. (2003). Mestres bantos da Alta-Mogiana: Tradição e memória da umbanda em Ribeirão Preto. Memorandum, 4, 05-32.

Lepine, C. (2009). O candomblé africanizado no campo religioso de São Paulo: Um balanço. Em L. N. Negrão (Org.), Novas Tramas do Sagrado: Trajetórias Multiplicidades (pp. 261-382). São Paulo: Edusp.

Macedo, A. C \& Bairrão, J. F. M. H. (2011). Estrela que vem do Norte: Os baianos na umbanda de São Paulo. Paidéia, 21(49), 207-216. http://dx.doi.org/10.1590/S0103863X2011000200008

Negrão, L. N. (1996). Magia e Religião na Umbanda. USP, (31), 76-89.

Negrão, L. N. (2008). Pluralismo e multiplicidades religiosas no Brasil contemporâneo. Sociedade e Estado, 23(2), 261279 http://dx.doi.org/10.1590/S010269922008000200004

Negrão, L. N. (Org). (2009). Novas tramas do sagrado: Trajetórias multiplicidades. São Paulo: Edusp.

Ortiz, R. (1991). A morte branca do feiticeiro negro: Umbanda e sociedade brasileira. São Paulo: Brasiliense.

Paiva, G. J. de. (1999). Imaginário, simbólico e sincrético: Aspectos psicológicos da filiação a novas religiões japonesas. Porto Alegre: Psicol. Reflexão Crítica, 12 (2), 521-535. http://dx.doi.org/10.1590/S0102-79721999000200017

Rabelo, M. (2015). Moving between religions in Brazil: Space and the analysis of religious trajectories. Current Anthropology, 56(6), 848-864. http://dx.doi.org/10.1086/684013

Ribas, O. (1989). Ilundu: Espíritos e ritos angolanos. Porto: Edições ASA.
Roberts, M. V. (2010). Religious belonging and the multiple. Journal of feminist studies in religion, 26(1), 43-62. http://dx.doi.org/10.2979/fsr.2010.26.1.43

Rotta, R. R. \& Bairrão, J. F. M. H. (2012). Sentidos e alcance psicológicos de caboclos nas vivências umbandistas. Memorandum, 23, 120-132.

Sanchis, P. (1997). As religiões dos brasileiros. Horizonte, 1(2), 28-43.

Scorsolini-Comin, F. (2014a). Atenção psicológica e umbanda: Experiência de cuidado e acolhimento em saúde mental. Estudos e Pesquisas em Psicologia. 14(3), 773-794.

Scorsolini-Comin, F. (2014b). Plantão psicológico centrado na pessoa: Intervenção etnopsicológica em terreiro de umbanda. Ribeirão Preto: Temas em Psicologia, 22(4), 885899. http://dx.doi.org/10.1590/1413-82712015200115

Silva, V. G. (2012). Exu do Brasil: Tropos de uma identidade afro-brasileira nos trópicos. Antropologia, 55(2). http://dx.doi.org/10.11606/2179-0892.ra.2012.59309

Slenes, R. (2011). Na senzala, uma flor - Esperanças e recordações na formação da família escrava: Brasil Sudeste, sec.XIX. Campinas: Unicamp.

Souza, M. M. (2002). Reis negros no Brasil escravista: História da festa de coroação de Rei do Congo. Belo Horizonte: UFMG. 